\title{
Effects of boar stimuli on the follicular phase and on oestrous behaviour in sows
}

\author{
P. Langendijk, N.M. Soede and B. Kemp \\ Department of Animal Science, Wageningen University, PO Box 338, 6700 AH Wageningen, \\ The Netherlands
}

This review describes the role of boar stimuli in receptive behaviour, and the influence of boar stimuli during the follicular phase. Receptive behaviour (standing response) in an oestrous sow is elicited by boar stimuli, which can be olfactory, auditory, tactile, or visual. The relative importance of these stimuli is not clear. Individually, olfactory and tactile stimuli elicit a standing response in a variable percentage of sows, depending on the study, but not in all sows. Nevertheless, both tactile and olfactory stimuli seem essential to elicit a standing response. Contact with a boar is always more potent than combinations of boar stimuli. Intensive boar contact can cause habituation, reducing the responsiveness to boar stimuli. It is not clear how behavioural oestrus is 'prepared' at the brain level. Oestrogens are a key factor in the neuroendocrine maturation that precedes oestrus. The opioid peptide system is probably also involved. Once a sow is in oestrus, the neuroendocrinological events that are triggered by boar stimuli, and that induce a standing response, are not well understood. Oxytocin and prolactin are both released during a standing response, and again, the opioid peptide system seems to be involved. Boar stimuli are also important during the follicular phase. In gilts and sows, follicle development and (first) oestrus is advanced by boar exposure. Although there is very little evidence for this, an increase in $\mathrm{LH}$ secretion, caused by contact with a boar, is probably the explanation. With respect to this mechanism, habituation to boar stimuli might also play a role.

\section{Introduction}

In most mammalian females, the period around ovulation is marked by oestrous behaviour. In sows, oestrus is normally defined as the period during which sows show receptive behaviour, i.e. a 'standing reflex', in reaction to certain stimuli. One or more stimuli are involved in courtship behaviour of the boar and in the act of mating, and can be olfactory (boar odor), visual (presence of the boar), auditory (boar grunts), and tactile (rubbing of back and flanks) (Signoret, 1970). Mimicking a combination of such stimuli can elicit receptive behaviour. Whether or not a sow will show receptive behaviour in reaction to certain stimuli depends on (1) the level, or 'potency' of such stimuli, and (2) on the responsiveness of the sow to the stimuli. Detection of receptive behaviour using boar stimuli is important for oestrus-based insemination strategies. 
Boar stimuli also affect follicle development leading to oestrus. This review focuses on the effect of boar stimuli on receptive behaviour, on neurophysiological aspects of receptive behaviour, and on the influence of boar stimuli during the follicular phase.

\section{Boar stimuli and induction of receptive behaviour}

\section{Expression of oestrous behaviour}

During the course of oestrus, responsiveness to stimuli, which evoke receptive behaviour, first increases to a peak, and then dissipates. As a consequence, during the course of oestrus, different phases can be distinguished, depending on the 'level' of the stimulus needed to evoke receptive behaviour. Willemse and Boender (1967) for example, distinguished an 'inseminator period', during which an inseminator could evoke a standing reflex by mimicking tactile boar stimuli (BPT: Back Pressure Test, manual stimulation of the back and flanks of a sow). This period covered the middle two-thirds of the 'boar period', the period during which physical contact with a boar would evoke a standing reflex. A person, therefore, was less potent in evoking oestrous behaviour than a boar, and consequently, the duration of oestrus recorded by a person was shorter than when using a boar. Several studies have focused on the potency of different stimuli or combinations of stimuli required to evoke receptive behaviour, and as such, on their effectiveness for detection of oestrus (Table 1). There are fundamental differences between studies in the approach used to compare different boar stimuli. In older studies (Signoret and Bariteau, 1975; Reed et al., 1974; Perry et al., 1980), the boar stimuli tested were applied only once during oestrus in sows that had been previously identified as being 'oestrous' using a boar, but had failed to show a standing response when a BPT was applied in absence of a boar. The stimuli that they tested were then applied and, depending on their potency and on the responsiveness of the different sows, elicited receptive behaviour in a certain percentage of the sows. Because the exact stage of oestrus was not known in these studies, the estimated potency of a combination of stimuli depended on the sample of sows in the study. A different approach is to apply a stimulus repeatedly throughout the whole period of oestrus and identify the cumulative percentage of sows that respond positively at any given time during oestrus. This second approach gives an estimation of the duration of oestrus in response to a particular stimulus. The second approach also gives an estimate of the number of sows in which oestrus can not be detected at all with a given stimulus (Langendijk et al., 2000a). This estimate is, therefore, probably higher than for the first approach. Another important factor is the way individual stimuli are presented to a sow. Natural or artificial components of boar stimuli can be presented individually, or in combinations. As Table 1 shows, the additive effect of a stimulus depends on whether it is presented alone, or in combination with one or more other stimuli, and, in the latter case, which stimuli are combined.

Because of the complex aspects pointed out above, it is difficult to draw conclusions about the relative importance of different boar stimuli in affecting receptive behaviour. Nevertheless, a BPT in the absence of a boar induced receptive behaviour in 27 to $92 \%$ of the sows, depending on the approach used in the study (Table 1). Although a BPT alone does not elicit receptive behaviour in all sows, tactile stimuli do seem essential. Only 50 to $68 \%$ of oestrous sows spontaneously showed a standing response when having nose-to-nose contact with an intact boar without further tactile stimuli (Langendijk et al., 2000a). A BPT in combination with boar odor, or components of boar odor, evoked a standing reflex in up to $60 \%$ of oestrous sows that were negative to a BPT alone (Signoret and Bariteau, 1975; Reed et al., 1974; Perry et al., 1980 ), indicating their added value to tactile stimuli. The important pheromones for eliciting receptive behaviour within the complex of boar odor are 5 -alpha-androstenone and 5-alpha- 
Table 1. Oestrous expression in response to different combinations of boar stimuli

Reference Stimulus ${ }^{*} \quad$ Percentage of sows showing oestrous behavior

Tests at one undefined point during oestrus ${ }^{a}$

Signoret \& Bariteau $(1975)^{\mathrm{a}} \quad$ Back pressure test (BPT)

Exp 2 BPT + sound + odor (boar behind screen)

39 to $60 \%$ (depending on stage of oestrus)

BPT + sound + odor + sight

$90 \%$

$97 \%$

full boar contact

$100 \%$

Exp 3 BPT + odor (emply boar pen) $60 \%$

Exp 4 BPT + sound (recorded boar grunting) $\quad 50 \%$

Reed et al. (1974)

BPT + boar odor

$60 \%$

BPT + synthetic odor

$46 \%$

Melrose et al. (1971)

BPT

BPT + synthetic odor

BPT + boar

$27 \% \mathrm{c}$

$31 \% \mathrm{c}$

$100 \% d$

Tests repeatedly throughout oestrus ${ }^{b}$

Langendijk et al. (2000a) ${ }^{b}$

Langendijk et al. $(2000 \mathrm{~b})^{\mathrm{b}}$

Gerritsen et al. (2005)

$$
\begin{aligned}
& \text { BPT } \\
& \text { BPT + Boar } \\
& \text { BPT in DMA (detection-mating-area; } \\
& \text { surrounded by } 4 \text { boar pens) }
\end{aligned}
$$

BPT

BPT + boar

Sight (plastic boar model)

Sight + sound (recorded boar grunting)

Sight + sound + synthetic odor

Real boar
$41 \%^{c}$
$88 \%^{d}$
$94 \%^{d}$

$92 \%$ c

$100 \% \mathrm{c}$

$75 \% \mathrm{c}$

$81 \% \mathrm{c}$

$66 \% \mathrm{c}$

$100 \% d$

\footnotetext{
aThese studies tested different stimuli in oestrous sows that did not show receptive behavior in response to only a BPT. Tests were performed at one point during oestrus. Stage of oestrus at which the tests were performed is not specified and differ between sows. bThese studies tested stimuli repeatedly throughout the entire period of oestrus. Percentages, therefore, indicate the number of sows that responded positively, at least once, giving a cumulative percentage of positive sows throughout oestrus. "Stimuli that are listed vertically within one study are superimposed. c,dDifferent superscripts indicate significant differences within one study; if no superscripts are given the study did not mention tests for significance.
}

androstenol (Hughes et al., 1990). These pheromones, among others, are communicated to the sow by boar saliva. The importance of boar odor is supported by the fact that boars without submaxillary salivary glands were incapable of evoking receptive behaviour in oestrous gilts (Perry et al., 1980). Addition of auditory stimuli evoked a standing response in about $50 \%$ of sows that were negative to a BPT alone. A combination of auditory and olfactory stimuli induced a standing response in up to $90 \%$ of such sows (Signoret, 1970), and the addition of more stimuli increased this to 97 (visual) and $100 \%$ (full boar contact). Full boar contact can be mimicked by combining several artificial stimuli. In a recent study, Gerritsen et al. (2005) combined synthetic visual, auditory, and olfactory stimuli by using a plastic model of a boar that emitted pre-recorded boar grunting and a synthetic boar odor (5-alpha-androstenone). The percentage of sows that was detected in oestrus ( $74 \%$ on average) did not increase after adding auditory and olfactory stimuli, and was lower than when using a boar (Table 1). The duration of oestrus was also shorter when using artificial stimuli: $36 \mathrm{~h}$ on average for combinations of artificial stimuli compared to $56 \mathrm{~h}$ when using a boar. 
From the above it appears that the use of a boar reduces the risk of 'missing' oestrous sows to a minimum. The question arises whether there is a combination of stimuli which is even more effective than just the presence of a boar. Hemsworth et al. (1991) designed a DetectionMating-Area (DMA), which consists of an open space surrounded by several boar pens. Stimulation of oestrous behaviour can be expected to be more intense in such a DMA. Langendijk et al. (2000a) compared the use of such a DMA to two other stimulus levels in the same group of sows. Oestrus detection was performed every $8 \mathrm{~h}$, and at each occasion, a BPT, a BPT in the presence of a boar, and a BPT in the DMA were applied consecutively in the same sows. Both the proportion of sows detected in oestrus and the recorded duration of oestrus increased with a higher stimulus level, although the proportion detected when using a boar or the DMA was not significantly different (Table 2). However, for a second group of sows that were not exposed to the DMA, and only tested using a BPT and a BPT in the presence of a boar, the proportion of sows detected in oestrus using a BPT was higher than for the first group of sows $(68 \%$ vs $41 \%$ ). In addition, the proportion of sows showing oestrus and duration of oestrus using a boar $(52 \mathrm{~h})$ in this second group did not differ from that in the first group of sows when using the DMA $(55 \mathrm{~h})$. The use of extra stimuli did not evoke more receptive behaviour; the sows adapted their responsiveness to the highest level of boar stimuli they were confronted with. Adaptation, or habituation to boar stimuli, was also described by Hemsworth and Hansen (1990) a id Dyck (1988), who both found that continuous housing adjacent to a boar reduced duration of oestrus in sows after weaning. In gilts, continuous housing adjacent to a boar resulted in a lower oestrus detection rate (Tilbrook and Hemsworth, 1990). In weaned sows, habituation occurred in a matter of days. Habituation was also related to the novelty of the stimuli that was involved. Caton et al. (1986) observed that a lower percentage of gilts showed oestrus when housed adjacent to a boar as opposed to gilts exposed to a boar for only 30 min daily. However, when the gilts housed adjacent to a boar were taken to a new pen and exposed to a new boar, the percentage of gilts expressing oestrus was not reduced.

Table 2. Oestrous expression using a boar or a Detection-Mating-Area (DMA)

\begin{tabular}{|c|c|c|c|c|}
\hline & \multicolumn{2}{|c|}{$\begin{array}{c}\text { Treatment } 1(n-22) \\
\text { Maximum stimulus level: BPT and boar }\end{array}$} & \multicolumn{2}{|c|}{$\begin{array}{c}\text { Treatment } 2(n-49) \\
\text { Maximum stimulus level: } 8 P T \text { in DMA }\end{array}$} \\
\hline & $\begin{array}{c}\text { Percentage } \\
\text { showing oestrus }\end{array}$ & $\begin{array}{l}\text { Duration of } \\
\text { oestrus, } h\end{array}$ & $\begin{array}{c}\text { Percentage } \\
\text { showing oestrus }\end{array}$ & $\begin{array}{c}\text { Duration of } \\
\text { oestrus, } h\end{array}$ \\
\hline BPT & $68^{2 \times} \times$ & $28^{\prime}$ & $41^{2, y} \%$ & $24^{2}$ \\
\hline BPT and boar & $91^{b, x} \%$ & $52^{\mathrm{b}, \mathrm{x}}$ & $88^{b, *} \%$ & $45^{\text {b.y }}$ \\
\hline BPT in DMA & & $94^{\mathrm{b} \%}$ & $55^{c, x}$ & \\
\hline
\end{tabular}

Sows were checked for oestrus every $8 \mathrm{~h}$. Within each treatment, oestrus was checked using different stimulus levels, starting with the lowest (BPT). Time between different stimulus levels was approximately $25 \mathrm{~min}$. $\triangle$ bDifferent superscripts indicate differences between stimulus level within one treatment. ${ }^{x, y}$ Different superscripts indicate differences between treatments at various stimulus levels. From Langendijk et al. (2000a)

A factor that has hardly been touched in the literature is the difference between boars in their ability to evoke receptive behaviour. The novelty effect described above indicates that different boars are perceived differently, at least by gilts. There is some evidence that agressiveness or 'pro-activeness' of the boar affects duration of oestrus (Soede and Kemp, 1997). In a T-maze approach, De Jonge et al. (1994) observed a clear preference for a particular boar when sows were in the proceptive phase of oestrus. This preference disappeared once the sows were in the receptive phase. In contrast, Tanida et al. (1991) observed that in a multi-sire mating area (3 boars mixed with 8 oestrous sows), some boars received more attention from sows than others. 
In summary, components of the boar stimulus were less potent than a 'whole' boar, and induced receptive behaviour in only a percentage of oestrous sows. Nevertheless, tactile stimuli as well as olfactory stimuli seem to play an essential role. A combination of different components of the boar stimulus increased the chance of inducing a standing response in oestrous sows, although the additive value of individual stimuli was lower when superimposed as compared to when they were tested individually. Some sows remain insensitive to certain stimuli throughout the entire period of oestrus. For oestrus-based insemination strategies it is, therefore, important to perform oestrus detection using a mature boar with adequate libido, and to prevent habituation of sows to a boar.

\section{Regulation of receptive behaviour}

During oestrus, a sow is responsive to boar stimuli in a way that is completely different from the period outside oestrus. It is not clear which neuroendocrine events are involved in initiating this behavioural change, and how the display of receptive behaviour is actualiy induced at the neuroendocrine level. As in many other species, pigs are exposed to elevated levels of oestrogens in the period preceding oestrus. In ovariectomised sows, treatment with oestrogens caused behavioural oestrus, and duration of oestrus was correlated with the dosage of oestrogens administered (Signoret, 1967; Dial et al., 1983). Soede et al. (1997) showed that, in spontaneously ovulating sows, duration of oestrus was not related to the level of circulating oestrogens, indicating that other factors are also important. In their study, tethered and loose-housed sows were compared. Tethered sows spent more time displaying stereotype behaviour (78\% vs 47 $\%$ ) and had a shorter duration of oestrus (42 vs $63 \mathrm{~h}$ ). The level of stereotype behaviour in tethered sows was inversely related to duration of oestrus. Stereotype behaviour is associated with the release of endogenous opioid peptides. Esbenshade \& Huff (1989) found that treatment with the opiate, morphine, during the period between oestradiol benzoate treatment and the display of oestrous behaviour ( 2 to 3 days) shortened duration of oestrus from $38 \mathrm{~h}$ to $21 \mathrm{~h}$ in ovariectomised gilts. Treatment with naloxone, an antagonist of endogenous opioid peptides, abolished this effect. These data indicate an involvement of endogenous opioid peptides in the changes at the brain level, which precede oestrus, and/or in the display of receptive behaviour during oestrus. Esbenshade and Huff (1989) also studied the role of GnRH in receptive behaviour. Their data seem to indicate that GnRH does not have the same facilitative role in expression of oestrous behaviour in pigs as it does in rats (Moss and McCann, 1973; Pfaff, 1973). The same seems to be true for the $\mathrm{LH}$ surge. The pre-ovulatory $\mathrm{LH}$ surge occurs around the onset of oestrus (Soede, 1997; van de Wiel, 1981), but is not necessary for the onset of oestrus, since sows with a longer duration of oestrus already showed receptive behaviour before elevation of plasma $\mathrm{LH}$ levels.

Apparently, oestrogens cause a certain maturation of the neuroendocrine system, which is needed to be able to respond to stimuli, and evoke receptive behaviour; and the endogenous opioid peptide system is involved. But what events are triggered by boar-related stimuli, and lead to a standing reflex? It was described above that olfactory stimuli play an important role in eliciting a standing response. Krzymowski et al. (1999) demonstrated a humoral pathway for uptake of boar pheromones from the nasal cavity and transfer to the pituitary and the rest of the brain. Spraying $5 \alpha$-androstenone, a component of boar odor, in front of the nose of a sow induced release of hypophyseal oxytocin during oestrus (Mattioli et al., 1986). Oxytocin was also released during mating (Claus \& Schams, 1990; Kotwica et al., 1995) and during fence line contact with boars (Langendijk et al., 2003; Fig. 1). In these studies the boar was introduced to the sow at the time of mating or oestrus detection. In a study by Mathiasen (2001), oxytocin 
release in reaction to a BPT was much less pronounced in sows that were housed beside the boar continuously compared to other studies. Mathiasen (2001) also provided some evidence for a refractory phase before a second release of oxytocin $(20 \mathrm{~min}$ in some, but over $60 \mathrm{~min}$ in other sows), but these data are difficult to apply to a situation where a stimulus is re-introduced at each new occasion. Prolactin was also released upon exposure to a boar, in the same surge like fashion as oxytocin (Prunier et al., 1987; Kotwica et al., 1995). What is the role, if any, of these pituitary hormones in oestrous behaviour? Treatment of gilts with naloxone increased the initial peak in oxytocin release shortly after presentation to a boar, but did not increase courting and copulative behaviour (Kotwica et al., 1995). On the other hand, treatment with bremazocine (an agonist of kappa-opioid receptors), strongly reduced the release of both oxytocin and prolactin, and shortened the time spent on courting and copulative behaviour. Inhibition of prostaglandin synthesis had the same effects on oxytocin and prolactin release and on sexual behaviour as treatment with bremazocine (Kotwica et al., 1995). Although performed with a limited number of animals, these data again indicate a role of the opioid peptide system in expression of receptive behaviour during oestrus, with or without oxytocin and prolactin involvement. It is clear that oxytocin is not necessary to display a standing response since oxytocin release did not occur in sows that showed a standing response to a BPT (Langendijk et al., 2003). However, Langendijk et al. (2003) found a positive association between the magnitude of oxytocin release after introduction of a boar and the time receptive behaviour was exhibited (Figure 1): below a peak level of $75 \mathrm{pg} / \mathrm{ml}$, duration of the standing response varied between 0.5 and 5 min, whereas above a peak level of $75 \mathrm{pg} / \mathrm{ml}$, duration was at least $4 \mathrm{~min}$. Therefore, oxytocin might have a facilitative role.

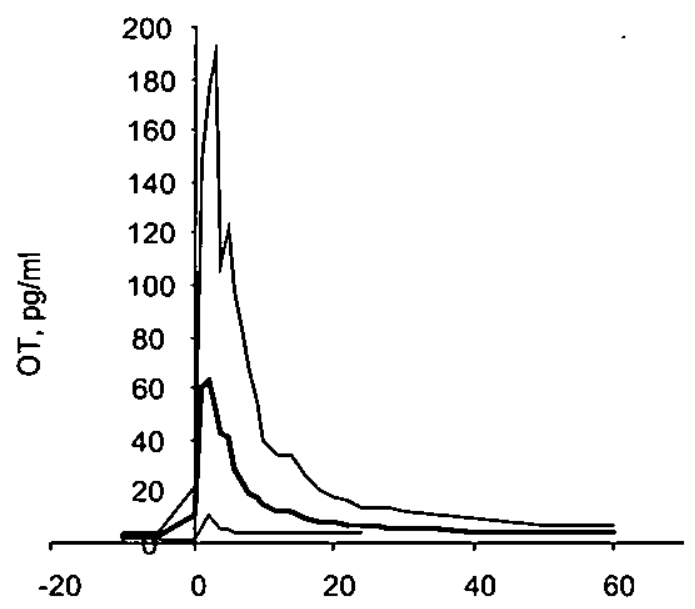

Time after introduction of boar, $\min$

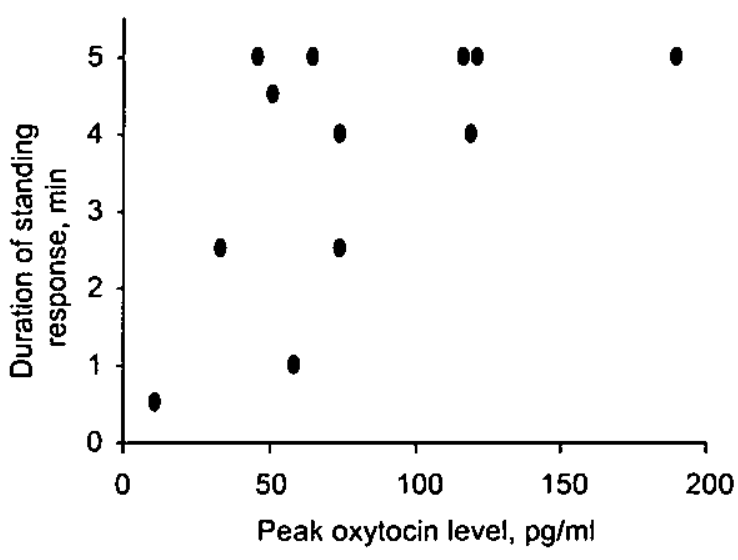

Fig. 1 Left panel. Oxytocin in peripheral plasma of oestrous sows after introduction of a boars. Time of entrance of the boar into the room $=0 \mathrm{~min}$. The boar only had fence-line contact with the sows. After $30 \mathrm{sec}$, a BPT was performed on the sows. The thick line represents the average of twelve sows. The upper and lower line represent two sows with the highest and lowest release of oxytocin. Right panel. The time during which the same sows remained 'frozen', showing a standing response, in relation to the peak level of oxytocin. After $5 \mathrm{~min}$, the boar was removed, and in all cases the sows ceased showing the standing response. [left panel from Langendijk et al. (2003)] 
Another factor that has received some attention in the literature is the release of cortisol during contact with a boar, especially in gilts (Pearce and Hughes, 1987; Barnett et al., 1982; Turner et al., 1998; Kotwica et al., 2002). The release of cortisol is assumed to indicate that introduction to a boar may, in fact, be aversive to the female, especially when she is not in oestrus. In a study with gilts, a BPT during fence line contact with a boar did not significantly increase blood cortisol levels, whereas full contact with a boar clearly did (Turner et al., 1998). It was hypothesised that the release of cortisol had negative effects on oestrus behaviour. However, there was no negative effect of introduction to a boar on any of the reproductive parameters studied. Repeated introduction to a boar even increased ovulation rate as discussed later.

In summary, oestradiol is the key hormone in the events that lead to behavioural oestrus. Oestradiol is probably responsible for a multitude of complex 'maturation' processes at the brain level. There are indications that the endogenous opioid peptide system is involved in this maturation, but much more research is needed to give a better understanding of the complexity of these processes in pigs. We are also beginning to understand neuroendocrine mechanisms that are involved in expression of a standing response. Whether oxytocin and prolactin are key factors, or are only co-released with other factors during mating, remains to be elucidated.

\section{The influence of boar stimuli on follicular development leading to oestrus}

Advancement of puberty in gilts by exposure to a mature boar was thoroughly reviewed by Hughes et al. (1990). Boar stimuli also advanced oestrus in weaned sows. Older studies demonstrated that daily exposure to boars resulted in shorter weaning-to-oestrus intervals and a higher percentage of sows showing oestrus within 10 to 16 days after weaning (Hemsworth et al., 1982; Walton, 1986; Pearce and Pearce, 1992). In these studies, average weaning-to-oestrus intervals in control groups were quite long ( $>10$ days), and the effects of boar exposure quite substantial: an advancement of oestrus by about 3 days (0.4 to 4 days). In a more recent study with relatively short rebreeding intervals (5 days), Hughes et al. (1998) did not find an effect of boar exposure on oestrus in weaned sows.

Thus, effects of boar stimuli on follicular development are more obvious in situations that limit or delay follicular growth and oestrus. Langendijk et al. (2000b) studied the effect of boar exposure on oestrus in 94 primiparous sows. These sows lost $25 \mathrm{~kg}$ of body weight after farrowing. Such a weight toss predisposes sows to delayed return to oestrus after weaning. In this study, boar exposure beginning at 3 days after weaning increased the percentage of sows that ovulated within 9 days after weaning from $30 \%$ to $51 \%$. Ovulating sows had more back fat at weaning than non-ovulating sows: 14 vs $12 \mathrm{~mm}$. More detailed analysis showed that boar stimulation resulted in additional sows ovulating between 6.5 and 9 days after weaning (Fig. 2). Ultrasonography showed that all sows showed initial follicular development during the first 4 days after weaning: from about $2.5 \mathrm{~mm}$ at weaning to about $4 \mathrm{~mm}$ in anovulatory sows and about $5.5 \mathrm{~mm}(P<0.05)$ in ovulatory sows. Weaning induced initial follicle growth, and boar stimuli sustained follicular growth towards ovulation in a number of sows that would otherwise have failed to ovulate.

Lactating sows are another example in which follicular growth is typically suppressed. The suckling-induced inhibition of follicular growth was, at least in part, counteracted by exposure to a boar. Boar exposure during the last week of lactation reduced the weaning-to:oestrus interval (Walton, 1986; Newton et al., 1987), indicating advanced follicular development at the time of weaning. Petchey and English (1980) group-housed lactating sows from the third week of lactation onwards and introduced a boar to half of the sows 4 days after grouping. Boar 
contact resulted in $10 \%$ of the sows ovulating during lactation, and an advancement in the weaning-to-oestrus interval from 10 to 4.7 days in sows which ovulated after weaning.

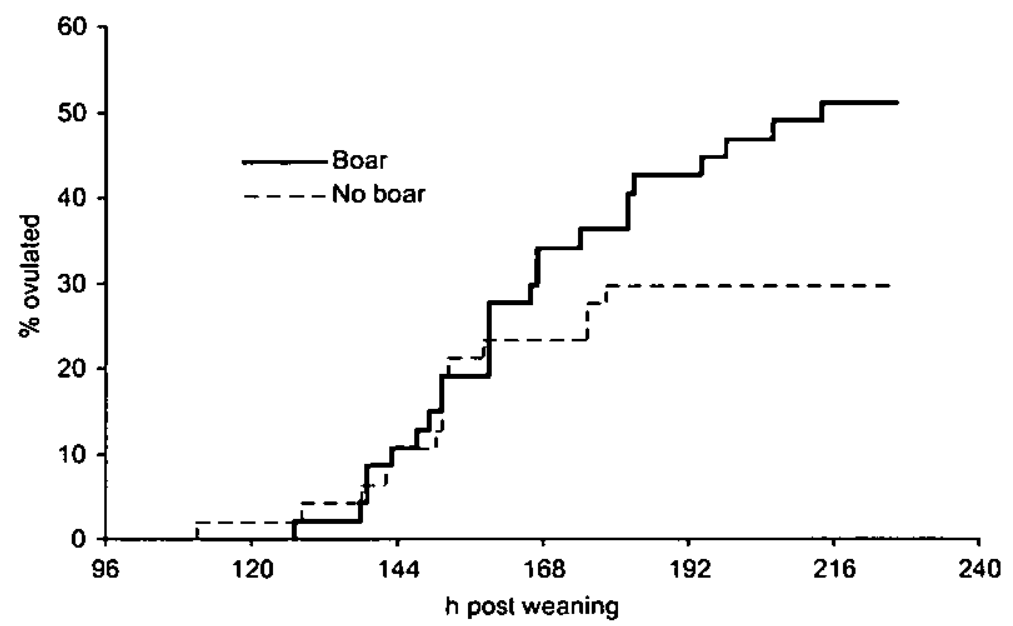

Fig. 2 Effect of boar contact on the cumulative percentage of primiparous sows 47 sows per treatment), which ovulated in relation to the time from weaning. Boar contact commenced 3 days after weaning. [Langendijk et al., 2000b]

Boar stimuli most likely act through neuroendocrine pathways that are involved in the secretion of $\mathrm{GnRH}$ by the hypothalamus, and therewith, secretion of $\mathrm{LH}$ and regulation of ovarian activity. In a 'normal' situation, sows display oestrus 4 to 7 days after weaning. Higher secretion of $\mathrm{LH}$ at the day of weaning resulted in a shorter weaning-to-oestrus interval (Shaw \& Foxcroft, 1985; van den Brand, 2000). Follicle growth in later stages of the follicular phase was also dependent on LH pulsatility (Driancourt et al., 1995; Guthrie et al., 1990). There are situations, in which LH secretion might be limiting for onset of ovarian activity, when boar stimuli might be helpful. Examples of such situations were given above. There is, however, very little evidence that boar stimuli affect $\mathrm{LH}$ release. In 3 sows that had been anoestrous for 21 days following weaning, $V$ an de $W$ iel et al (1993) found an increase in pulsatile release of $\mathrm{LH}$ when the sows were introduced to a boar (Fig. 3). Following introduction of the boar, the boar was housed continuously in the vicinity of the sows (across an aisle). In the preceding 21 days, $\mathrm{LH}$ release was not significant in these sows. Despite an increase in $\mathrm{LH}$ secretion after introduction of the boar, the 3 sows did not show ovarian activity within a week following introduction of the boar. In the same study, only 3 out of 7 anoestrous sows, which were treated with PG600, reacted with a clear rise in blood oestradiol and displayed behavioural oestrus, indicating that sensitivity of the ovaries to gonadotrophins was also involved. Moreover, some sows that apparently had the same LH release pattern as 'normal' sows, remained anoestrous. In a study of Kingsbury and Rawlings (1993), 17 gilts were exposed to a boar from 135 days of age, and 5 control gilts were not exposed to a boar. Twelve of these 17 gilts showed oestrus before 200 days of age; at an average of 169 days of age ('responders'), and 5 did not show oestrus before 200 days ('non responders'). The 5 control sows showed oestrus at an average age of 193 days. The 12 'responders' and the 5 'nonresponders' had an increase in LH pulse frequency after introduction of the boar: from $0.26 \mathrm{~h}^{-1}$ during $6 \mathrm{~h}$ before to $0.57 \mathrm{~h}^{-1}$ during $6 \mathrm{~h}$ after boar introduction $(P<0.01)$ in the 'responders' and from 0.31 to $0.50 \mathrm{~h}^{-1}$ ( $P$ value not given) in the 'nonresponders'. In gilts that were not exposed to boars, there was no increase in LH pulse 

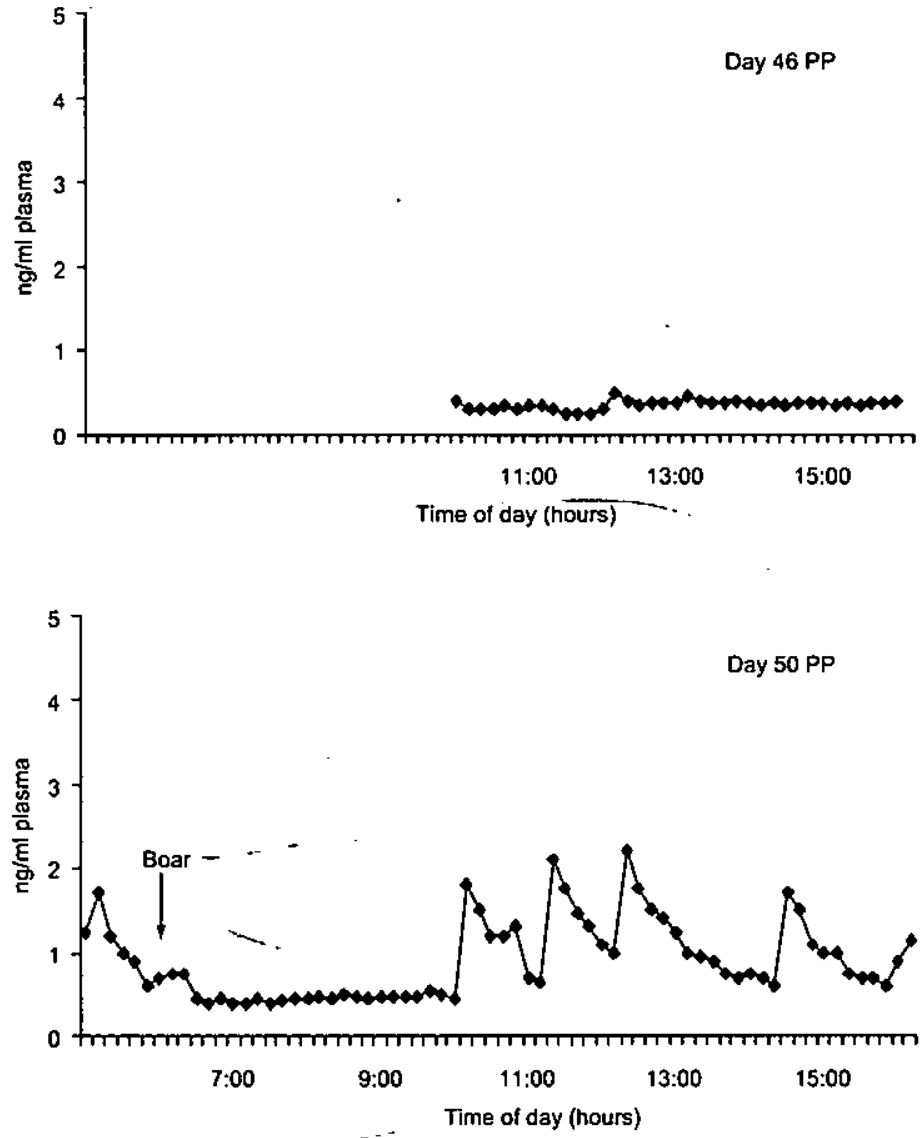

Fig. 3 Peripheral plasma $\mathrm{LH}$ concentrations $(\mathrm{ng} / \mathrm{ml})$ in a sow that was anoestrous for 21 days after weaning, which was 28 days postpartum (PP). On Day 50 PP, a boar was introduced and was housed continuously in the vicinity of the sow. The sow did not show ovarian activity in the following 7 days. [after Van de Wiel and Booman (1993)]

frequency $\left(0.31 \mathrm{~h}^{-1}\right.$ during both the first and second $6 \mathrm{~h}$ of sampling). Anoestrus in the 'nonresponders', despite increased LH secretion, might again be explained by an insufficient responsiveness of the ovaries to gonadotrophins. In addition, as in the study by Van de Wiel et al. (1993), the boars were housed near the gilts continuously after introduction. Ten days after introduction, LH pulse frequency decreased again to $0.35 \mathrm{~h}^{-1}$ in the nonresponders.

In summary, in sows with limited follicular development, boar contact restored follicular development leading to ovulation. Stimulation of LH release by boar contact is probably the factor explaining this effect. When boar contact commenced on the day of weaning or even earlier, oestrus was advanced, and the number of,sows in which follicular growth was sustained until ovulation increased. It is interesting to speculate how much, and with what frequency, boar contact is needed to adequately stimulate $\mathrm{LH}$ release. From the above, it appears that discontinuous boar contact is preferable. In the studies where oestrus was advanced in gilts or in sows after weaning, boar exposure was mostly a few minutes to half an hour one to three times a day (Walton, 1986; Pearce and Pearce, 1992; Langendijk et al., 2000b). Hughes (1993) showed that, in gilts, boar contact 2 or 3 times daily was more effective in inducing puberty than once 
daily or every other day. From the data of Van de Wiel et al. (1993), it seems that LH release is stimulated for at least $7 \mathrm{~h}$ beginning 3 to $4 \mathrm{~h}$ after boar introduction. These data were collected in only 3 sows, which were anoestrous for 3 weeks after weaning. More research is needed to clearly understand how boar contact affects $\mathrm{LH}$ release.

\section{Concluding remarks}

From the data presented in this paper it is clear that boar stimuli are important in stimulating follicular development and in expression of oestrous behaviour in sows. The relative importance of different stimuli in eliciting receptive behaviour is still not completely clear. It is clear that individual stimuli or combinations of stimuli are not as effective as a boar in eliciting receptive behaviour. However, differences between boars have to be recognised. The physiological mechanisms that are involved in expression of a standing response, triggered by boar stimuli, deserve further research. The influence of boar stimuli on foliicular development is probably mediated through the hypothalamus-pituitary axis, but there is still little evidence for this and for other possible factors involved.

\section{References}

Barnett JL, Hemsworth PH and Cronin GM (1982) The effect of mating on plasma corticosteroids in the female pig and the influence of individual and group penning on this response General and Comparative Endocrinology 47 516-521

Caton JS, Jesse GW, Day BN and Ellersieck MR (1986) The effect of the duration of boar exposure on the frequency of gilts reaching first estrus Journal of Animal Science $62 \quad 1210-1214$

Claus R and Schams D (1990) Influence of mating and intra-uterine estradiol infusion on peripheral oxytocin concentrations in the sow Journal of Endocrinology $126361-365$

De longe FH, Mekking P, Abbott $K$ and Wiepkema PR. (1994) Proceptive and receptive aspects of oestrus behaviour in gilts Behavioural Processes 31157. 166

Dial GD, Dial OK, Bevier GW, Glenn SD and Dziuk PJ (1983) Estrous behaviour and circadian discharge of $\mathrm{LH}$ in the prepubertal gilt in response to exogenous estrogen Biology of Reproduction 29 1047-1056

Driancourt MA, Locatelli A and Prunier A (1995) Effects of gonadotrophin deprivation on follicular growth in gilts Reproduction Nutrition and Development $\mathbf{3 5}$ 663.673

Dyck GW (1988) The effect of housing facilities and boar exposure after weaning on the incidence of postlactational anestrus in primiparous sows Canadian Journal of Animal Science 68 983-985

Esbenshade KL and Esbenshade KL. (1989) Involvement of hypothalamic compounds in the expression of oestrus in the pig Animal Reproduction Science 18 51-59

Gerritsen RG, Langendijk P, Soede NM, Kemp B (2005) Effects of artificial boar stimuli on the expression of oestrus in sows Applied Animal Behaviour Science In press

Gilbert CL, Jenkins $K$ and Wathes DC (1991) Pulsatile release of oxytocin into the circulation of the ewe during oestrus, mating and the early luteal phase Journal of Reproduction and Fertility $91337-346$

Guthrie HD, Bolt DJ and Cooper BS (1990) Effects of gonadotrophin treatment on ovarian follicle growth and granulosa cell aromatase activity in prepuberal gilts Journal of Animal Science 68 3719-3726

Hemsworth PH and Hansen C (1990) The effects of continuous boar contact on the oestrus detection rate of weaned sows. Applied Animal Behaviour Science 28 28t-285

Hemsworth PH, Salden NTC and Hoogerbrugge A (1982) The influence of the post-weaning social environment on the weaning to mating interval of the sow Animal Production 35:41-48

Hemsworth PH, Hansen C, Coleman GJ and Jongman E (1991) The influence of the conditions at the time of mating on reproduction of commercial pigs Applied Animal Behaviour Science 30 273-285

Hughes, PE (1993) The role of boar contact frequency in modifying the efficacy of the boar effect. In Manipulating pig production IV pp250 Ed ES Batterham. Australian Pig Science Association, Attwood, Victoria, Australia

Hughes PE (1998) Effects of parity, season and boar contact on reproductive performance of weaned sows Livestock Production Science 54 151-157

Hughes PE, Pearce GP and Paterson AM (1990) Mechanisms mediating the stimulatory effects of the boar on gilt reproduction Journal of Reproduction and Fertility Supplement 40 323-341

Kingsbury DL and Rawlings NC (1993) Effect of expo- 
sure to a boar on circulating concentrations of $\mathrm{LH}$, $\mathrm{FSH}$, cortisol and oestradiol in prepubertal gilts fournal of Reproduction and Fertility 98 245-250

Kotwica G, Sobczak J and Koziorowski M (1995) Effects of opioid peptides, indomethacin and age on oxytocin and prolactin release during mating in sows Reproduction in Domestic Animals 30 257-263

Krzymowski T, Grzegorzewski W, StefanczykKrzymowska S, Skipor / and Wasowska B (1999) Humoral pathways for transfer of the boar pheromone, androstenol from the nasal mucosa to the brain and hypophysis of gilts Theriogenology 52 12251240

Langendijk P, Soede NM and Kemp B (2000a) Effects of boar contact and housing conditions on oestrus expression in weaned sows fournal of Animal Science $78871-878$

Langendijk $P$, Van den Brand $H$, Soede NM and Kemp $B$ (2000b) Effect of boar contact on follicular development and on oestrus expression after weaning in primiparous sows Theriogenology 54 1295-1303

Langendijk P, Bouwman EG, Schams D, Soede NM and Kemp B (2003) Effects of different sexual stimuli on oxytocin release, uterine activity and receptive behaviour in oestrous sows Theriogenology 59849 861

Mathiasen J (2001) Human stimulation and re-stimulation increases the release of pituitary oxytocin in multiparous oestrous sows MSc Thesis Royal Veterinary and Agricultural University, Kopenhagen

Mattioli M, Galeati G, Conte F and Seren E (1986) Effect of 5á-Androst-16-en-3-one on oxytocin release in oestrous sows Theriogenology $25 \quad 399-403$

Moss RL and McCann SM (1973) Induction of mating behaviour in rats by luteinizing hormone releasing factor Science 181 177-179

Newton EA, Stevenson IS and Davis DL (1987) Influence of duration of litter separation and boar exposure on estrous expression of sows during and after lactation Journal of Animal Science 65 1500-1506

Pearce GP and Hughes PE (1987) An investigation of the roles of boar component stimuli in the expression of proceptivity in the female pig Applied Animal Behaviour Science 18 287-299

Pearce GP and Pearce AN (1992) Contact with a sow in oestrus or a mature boar stimulates the onset of oestrus in weaned sows Veterinary Record 130 5-9

Perry GC, Patterson RLS, MacFie HJH and Stinson CG (1980) Pig courtship behaviour: pheromonal property of androstene steroids in male submaxillary secretion Animal Reproduction Science 31 191-199

Petchey AM and English PR (1980) A note on the effects of boar presence on the performance of sows and their litters when penned as groups in late lactation Animal Production 31 107-109

Pfaff DW (1933) Luteinzing hormone-releasing factor potentiates lordosis behavior in hypophysectomized ovariectomized female rats Science 182 1148-1149

Prunier A, Martinat-Botte F, Ravault IP and Camous S (1987) Peri-oestrus patterns of circulating I.H, FSH, prolactin and oestradiol-17B in the gilt Animal Reproduction Science 14 205-218

Reed HCB, Melrose DR and Patterson RLS (1974) Androgen steroids as an aid to the detection of oestrus in pig artificial insemination British Veterinary Journal $13061-67$

Shaw HJ and Foxcroft GR (1985) Relationships between LH, FSH and prolactin secretion and reproductive activity in the weaned sow Journal of Reproduction and Fertility $75 \quad 17-28$

Signoret JP (1967) Duree du cycle oestrien et de l'oestrus chez la truie. Action du benzoate d'oestradiol chez la femelle ovariectomisee [Duration of the oestrous cycle and oestrus in the sow. Effect of oestradiol benzoate in the ovariectomised female]. Annales de Biologie Animale Biochemie et Biophysique 7 407421

Signoret JP (1970) Reproductive behaviour of pigs Journal of Reproduction and Fertility Supplement 11105 . 117

Signoret JP and Bariteau J (1975) Utilisation de differents produits odorants de synthese pour faciliter la detection des chaleurs chez la truie The use of different synthetic odours to facilitate heat detection in the sow] Annales Zootechniques 24 639-643

Soede, NM (1993) Boar stimuli around insemination affect reproductive processes in the pig: A review. Animal Reproduction Science 32 107-125

Soede, NM and Kemp B (1997) Expression of oestrus and timing of ovulation in pigs Journal of Reproduction and Fertility Supplement 52 91-103

Soede NM, Helmond FA, Schouten WGP and Kemp B (1997) Oestrus, ovulation and periovulatory hormone profiles in tethered and loose-housed sows Animal Reproduction Science 46 133-148

Tanida H, Miyazaki N, Tanaka T and Yoshimoto T (1991) Selection of mating partners in boars and sows under multi-sire mating Applied Animal Behaviour Science 32 13-21

Tilbrook Af and Hemsworth PH (1990) Detection of oestrus in gilts housed adjacent or opposite boars or exposed to exogenous boar stimuli Applied Animal Behaviour Science 28 233-245

Turner AI, Hemsworth PH, Hughes PE, Canny BJ and Tilbrook AJ (1998) The effect of repeated boar exposure on cortisol secretion and reproduction in gilts Animal Reproduction Science 51 143-154

Van den Brand, H, Dieleman SI, Soede NM and Kemp B (2000) Dietary energy source at two feeding levels during lactation in primiparous sows. I Effects on glucose, insulin and $\mathrm{LH}$ and on follicle development, weaning to estrus interval and ovulation rate Journal of Animal Science 78 396-404

Van de Wiel DFM and Booman P (1993) Post weaning anoestrus in primiparous sows: $\mathrm{LH}$ patterns and effects of gonadotropin injection and boar exposure Veterinary Quarterly $15 \quad 162-166$

Van de Wiel DFM, Erkens I, Koops W, Vos E and Van Landenghem (1981) Periestrous and midluteal time courses of circulating LH, FSH, prolactin, E2-17â 
and progesterone in the domestic pig Biology of Reproduction 24 223-233

Walton IS (1986) Effect of boar presence before and after weaning on oestrus and ovulation in sows Journal of Animal Science 62 9-15

Willemse, AH \& Boender J (1967) The relation between the time of insemination and fertility in gilts Tijdschrift Diergeneeskunde $92 \quad$ 18-34 